10. Bachmanov D. M., Kozhurin A. I., Trifonov V. G. The active faults of Eurasia database. Geodynamics \& Tectonophysics. 2017. Vol. 8(4). p. 711-736.

11. Lobatskaya R. M. Neotectonic fault-block structure of junction of Siberian Platform and West Siberian Plate. Geologiya i Geofizika. 2005. Vol. 46(2). p. 141-150.

12. Gvishiani A. D., Tatarinov V. N., Kaftan V. I., Manevich A. I., Dzeboev B. A., Losev I. V. The velocities of modern horizontal movements of Earth crust in the South sector of Yenisei Ridge according to GNSS observations. Doklady Earth Sciences. 2020. Vol. 493(1). p. 73-77. DOI: 10.1134/S1028334X20070077

13. Tatarinov V. N., Morozov V. N., Kaftan A. I., Manevich A. I. Modern geodynamics of the southern of the Yenisei Ridge derived from the results of satellite observations. Geophizicheskie issledovaniya. 2018. Vol. 19(4). pp. 64-79.

14. Manevich A. I., Tatarinov V. N., Kolikov K. S. Detection of crustal deformation anomalies with regard to spatial scale effect. Eurasian Mining. 2019. No. 2. pp. 19-22. DOI: 10.17580/ em.2019.02.04

15. Wright T. J., Lou Y., Zhang R., Zhang W., Shi C., Huang J., Na Wei. Crustal Deformation in the India-Eurasia Collision Zone
From 25 Years of GPS Measurements. 2017. Journal of Geophysical Research: Solid Earth. 2017. Vol. 122. pp. 9290-9312.

16. Roštínský P., Pospíšil L., Švábenský O., Kašing M., Nováková E. Risk faults in stable crust of the eastern Bohemian Massif identified by integrating GNSS, levelling, geological, geomorphological and geophysical data. Tectonophysics. 2020. Vol. 785. 228427.

17. Vernikovsky V. A., Metelkin D. V., Vernikovskaya A. E., Matushkin N. Y., Kadilnikov P. I. et al. Neoproterozoic tectonic structure of the Yenisei ridge and formation of the western margin of the Siberian craton based on new geological, paleomagnetic, and geochronological data. Russian Geology and Geophysics. 2016. Vol. 57(1). pp. 47-68.

18. Kuzmin Y. O. Recent geodynamics of dangerous faults. Izvestiya. Physics of the Solid Earth. 2016. Vol. 52, No. 5. pp. 709-722.

19. Morozov V. N., Tatarinov V. N., Manevich A. I., Losev I. V. Analogy method to determine the stress-strain state of structuraltectonic blocks of the Earth's crust for the disposal of radioactive waste. Russian Journal of Earth Sciences. 2019. Vol. 19. DOI: $10.2205 / 2019 E S 000687$ 테

Yu. P. GALCHENKO ${ }^{1}$, Expert, Doctor of Engineering Sciences, Professor

V. A. EREMENKO ${ }^{7}$, Director of Research Center for Applied Geomechanics and Convergent Mining Technologies, Doctor of Engineering Sciences, Professor of the Russian Academy of Sciences, prof.eremenko@gmail.com

N. G. VYSOTIN ${ }^{1}$, Senior Lecturer

M. A. KOSYREVA ${ }^{1}$, Post-Graduate Student

${ }^{1}$ NUST MISIS College of Mining, Moscow, Russia

\title{
JUSTIFICATION OF FUNCTIONAL ORGANIZATION AND CONTENTS OF MODELING CLUSTER CONCEPT FOR GEOMECHANICAL RESEARCH OF CONVERGENT MINING TECHNOLOGIES*
}

\section{General provisions}

Regarding the impact on the environment (or lithosphere, in our case), the key difference of the nature-like convergent mining technologies from the conventional geotechnologies is the indispensable preventive negotiation with geomechanical after-effects of mining-induced damage. Modeling should always take this fact into account and should assume the time effect as the advanced implementation of ground control in the course of stoping.

The governing criteria and constants of modeling a technology cluster are selected from the dynamic similarity law. In this case, the modeling reveals the stress-strain behavior of a mining system and its components subject to the breakage and drawing conditions
The new scientific school on the nature-like convergent mining technologies, which assume preventive negotiation of geomechanical consequences of mining-induced damage in the lithosphere, requires adjustment of the conventional modeling methods using the factor of time. In the framework of the main theories of similarity, the comparative studies of different model material composition are carried out, and the formula of solidifying mixtures is justified for equivalent materials for modeling joint loading of manmade and natural components of geotechnical systems. An original procedure is proposed for the construction of block models by means of gluing, such that the unit block sizes are determined in terms of sizes blocks generated by joint systems, and the number and location of gluing points are selected as function of condition of healed joints. The new procedure efficiency is checked by the method of calibration and comparison of the modeling data with the quantitative assessments of the real-life rock masses. For different mining systems, the interpolating functions of the influence factor are plotted to image the rock mass stability categories. The new instrumentation is created for the integrated test workbenches, which provides integrated patterns of strength, deformation and acoustic characteristics of physical models of the proposed convergent geotechnical systems, the obtained values of the strength and deformation characteristics of the physical models made it possible to calibrated the relevant numerical models based on the retrospective analysis of deformation process evolution. It has been proved for the first time that the values of microstrains can be used as the indicators of the secondary stress field in the structure of anthropogenically altered subsoil as an independent object in the lithosphere.

Keywords: Convergent mining technologies, geomechanics, secondary stress field, similarity theory, modeling, clusters, procedure, model material, calibration, experiment

DOI: $10.17580 /$ em.2021.02.03

*The study was supported by the Russian Science Foundation, Project No. 19-17-00034. 
Table 1. Properties and composition of equivalent geomaterial

\begin{tabular}{|l|c|}
\hline Ultimate compression strength, MPa & $15-19$ \\
\hline GSI (Geological Strength Index) & $51-58$ \\
\hline Structural index mi & $7-8$ \\
\hline Deformation modulus, GPa & $9.8-19.6$ \\
\hline Cohesion, MPa & $0.687-0.73$ \\
\hline Internal friction angle, degree & $25.404-27.03$ \\
\hline Poisson's ratio & $0.165-0.25$ \\
\hline Water absorption, \% & $13-16$ \\
\hline Hoek-Brown constant $m b$ & $3.895-3.931$ \\
\hline Hoek-Brown constant $s$ & $0.002-0.0021$ \\
\hline Hoek-Brown constant $a$ & $0.504-0.506$ \\
\hline Density, kg/m ${ }^{3}$ & $1800-2000$ \\
\hline Common ground quicklime,$\%$ & $5-8$ \\
\hline Unground quartz sand, \% & $82-87$ \\
\hline Cement, \% & $8-10$ \\
\hline Water, \% & 7 \\
\hline
\end{tabular}

per blocks, and also depending on the sequence of mining within the limits of an extraction block.

\section{General approaches}

A fundamental basis of modeling as a universal method of research is the theory of similarity and the dimension theory $[1,2]$.

The first and second theorems of similarity set properties of the phenomena but offer no method to be used to determine similarity of the phenomena being compared. The answer is given in the third theorem: "Phenomena, which take place in the geometrically similar systems and which obey the same equations of connections, such that the values and parameters they include are at the constant numerical ratios and the criteria composed of them are equal, are similar" [1, 3].

Based on the aforesaid, we formulate conditions to be obeyed for the phenomena to be similar:

1. Geometrical similarity of systems and literal sameness of equations of connections;

2. Similarity of single-valuedness conditions;

3. The similarity indicators composed of the constant values included in the single-valuedness conditions are equal to one.

The last condition agrees with the condition of equality of criteria composed of the same values and parameters. These criteria are the constitutive criteria as their invariance is included in the conditions of similarity of phenomena.

The single-valuedness conditions should fixate geometrical characteristics of phenomena, numerical values of physical constants, and the boundary and initial conditions.

The research into under-studied mechanical processes (events induced by lithostatic pressure, etc.), when it is difficult to construct a differential equation of connection, begins with a simpler approach to finding the required similarity constants and criteria, namely, the Newtonian law of dynamic similarity in combination with the dimension method.
The aim of the experiments is finding the influence of shape, size and layout of manmade voids on the stability and strength of a unit block [4].

\section{Model material selection justification}

The model material having strength and density similar to rocks was selected after testing physical and mechanical properties of rocks from the deposits in the Norilsk Region, Yakutia, West Siberia, Ural, Buryatia and Western Australia. The deposits were chosen from the criterion of applicability of the convergent mining technologies being developed by the present authors. The semi automatic hydraulic test machine $\mathrm{P}-125$ used in the tests allows measurement and determination of absolute and relative longitudinal deformations. Lateral deformations are measured using foil strain gauges FK.

The test samples were made of core taken in rock mass or from a muck pile. The samples had a height of $80 \mathrm{~mm}$ and a diameter of $40 \mathrm{~mm}$.

During the tests, we plotted deformation diagrams using $\mathrm{M}$-Test software reading out information on loads and deformations from the P-125 machine controller. The software makes it possible to obtain the loading-deformation, loadingtime and deformation-time plots.

First, we determined the strength properties of the test sample and, second, their deformation characteristics to conform with the strength properties. The deformation pattern included loading of the samples up to $50 \%$ of the ultimate strength and total unloading later on. Second, we analyzed the deformation curves and determined the deformation and elasticity moduli, and Poisson's ratio.

The database on physical/mechanical properties and quantitative indicators of rocks and rock masses, compiled in the course of the studies, was used in physical modeling of frame and honeycomb mine structures made from equivalent materials and rocks (beige and grey dolomite, halite, magnetite, polyhalite, polymineral salts, etc.) and in numerical modeling of the conventional and frame mine structures.

Furthermore, in the test period, we worked out a few mix formulations for equivalent materials to build solid and blockstructured physical models. The mix formulations were found experimentally from mixing different components at different ratios. After hardening, the samples of the equivalent materials were subjected to the tests to determine their physical and mechanical properties (Table 1).

\section{Model preparation}

We carry out experiments on block models as the block structure is native to a real-time rock mass. In the framework of the research, we also developed a procedure and workbenches for making physical models of equivalent materials, including 3D modeling of any complexity.

Regarding modeling, we adhered to the procedure as follows: structural components of physical models were designed in AutoCAD; the designed components were 3D printed (Fig. 1) using PLA or ABS plastics; die molds were manufactured on a special workbench for making physical models of any complexity; components of an equivalent material were mixed in special reservoirs; the prepared equivalent material was poured into die molds to manufacture structural components of the future physical models; the cured equivalent material was taken out of the multiple-use die molds; the structural components are glued together using a hardening 


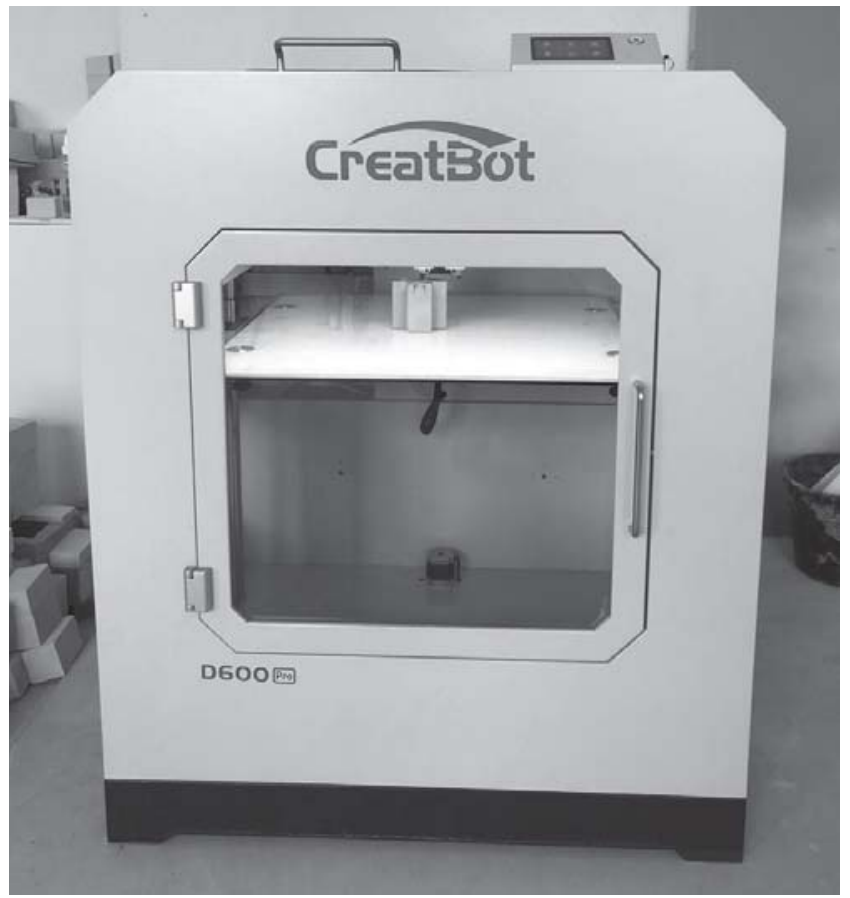

Fig. 1. 3D printer CreatBoot d600Pro and a structural component of a physical model

solution or a polymer adhesive with high bonding force and intended for gluing concrete products; then, in 15 days, the physical models were subjected to testing.

On the basis of goals and objectives of physical models of new geotechnical systems, and frame and honeycomb mine structures, we made and tested 7-12 models in each series of experiments. The models had different shapes and layout of voids, and different sizes and thicknesses of the framing. As a result of the modeling, we determined the optimal way of extracting material from a block and found the model parameters such that the system possesses the maximum stability under external loading.

\section{Testing equipment and procedure for physical models}

The stress-strain behavior of the physical models and geotechnical systems in the secondary stress field is assessed using the Hoek-Brown failure criterion which is a function of principal stresses and strength of rock masses. The rock mass properties beyond the limits of anthropogenically altered subsoil zone are determined in RocData program (License No. 19009-001), entered with data on the properties of rock samples and with quantitative characteristics of rock mass (GSI, etc.).

The physical models are composed of the structural components in the form of rectangular parallelepipeds. In this fashion, the models consist of unit blocks and have three systems of joints with certain conditions at contacts in the Cartesian axes. The systems of joints in a model are the contacts of the glued unit blocks. We should emphasize that it is for the first time that the quality of an equivalent material representing rock mass in the physical models is assessed using Barton's $\mathrm{Q}$-system. The estimation included the influence exerted on the physical model strength by: the quality of the material; the

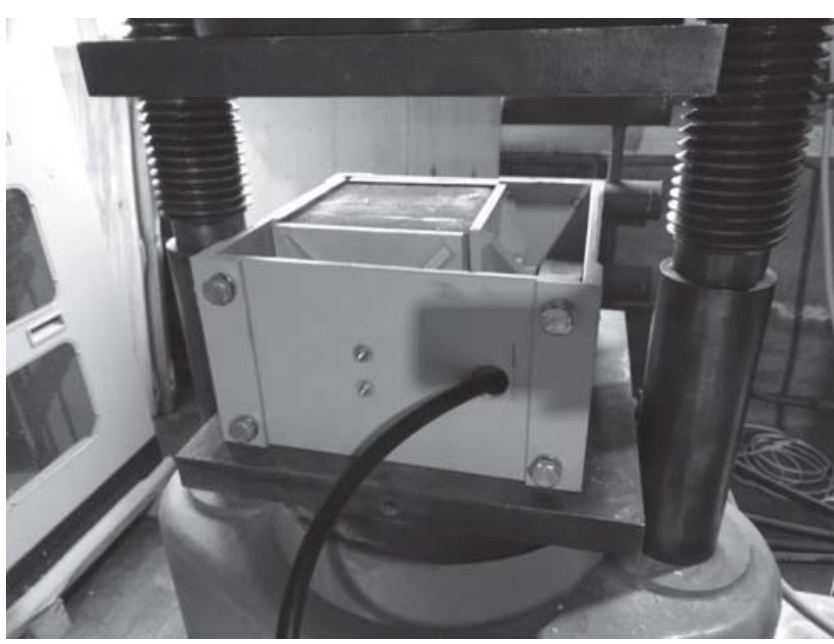

Fig. 2. Workbench for integrated strength, deformation and acoustic testing of physical models and their structural components under three-axial loading and simulated gravitational tectonic and lithostatic initial geo-stress state

number of the joint systems; the joint alteration and roughness. The equivalent material used to make the experimental physical model had $Q=5.5$. The workbench designed and constructed for the physical and optical modeling of geomechanical processing in the secondary stress field in rock mass in the course of mining is shown in Fig. $2[5,6]$.

Within the R\&D research, we also designed and constructed a single-purpose workbench for the reproduction of physical models of any complexity with the components manufactured by 3D modeling (3D printing).

\section{Lab-scale experimental results}

The geomechanical models of the new-proposed frame mine structures are created as the standard engineering solutions for the averaged geological conditions of mining, and are calibrated using the quantitative estimates of real-life rock mass conditions.

The modeling and calibration provide stress-strain patterns in rock mass under anthropogenic impact. The key part in generation of shapes and sizes of tensile strain zones and in distribution of microstrains in rock mass belongs to the shapes and sizes of manmade discontinuities (stopes) within the limits of the conventional and new mine structures (Fig. 3). In this connection, for evaluating the change in the initial stress field in the course of mining, we have introduced and justified the influence factor $E_{M}$ which is a ratio of geometrical parameters of interacting components:

$$
E_{M}=S_{\mathrm{d} . \mathrm{s}} K_{K} / S_{\varepsilon \mu}
$$
where $S_{\text {d.s }}$ is the area of external outline of a mine structure (structural components) in a given mining system, $\mathrm{m}^{2} ; S_{\varepsilon \mu}$ is the area of external outline of the tensile strain zone with the values $\varepsilon_{\mu}=\varepsilon_{\mu}^{k}$ at its boundary; $K_{K}$ is the calibration coefficient.

In two-dimensional case (in cross-section of a mining system), the calculation formula is given by:

$$
E_{m p}=P_{\text {d.s }} K_{K} / P_{\varepsilon \mu} \text {, }
$$
where $E_{m p}$ is the local influence factor; $P_{\text {d.s }}$ is the external perimeter of mine structure in cross-section of mining system, 

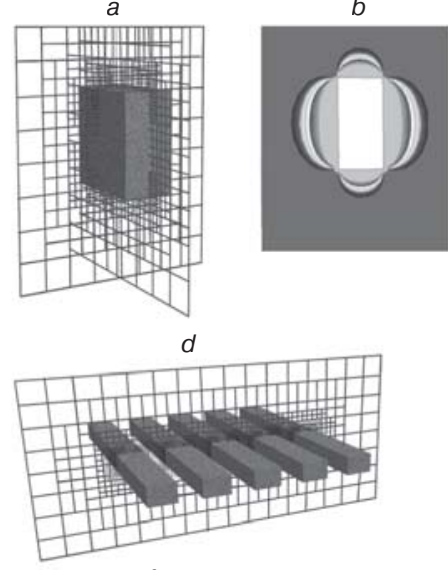

$f$

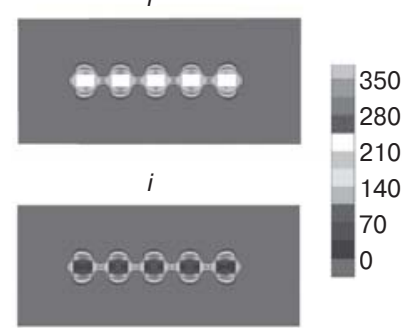

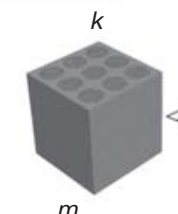

$m$

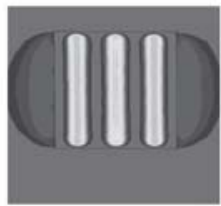

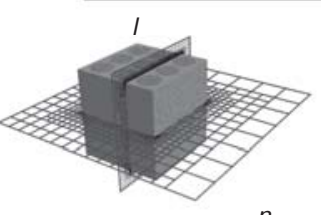

$n$
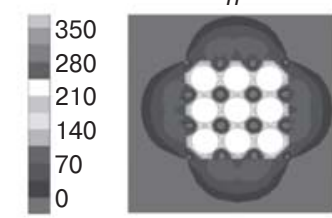

Fig. 3. Zones of tensile strains in rock mass in the course of $(a-c)$ block caving; $(d-g)$ open stoping; $(h, i)$ cut-and-fill mining; $(j-m)$ frame-structured geotechnical system with backfill composed of barren rocks or mining waste; 0-350microstrains $\varepsilon \mu$

$\mathrm{m} ; P_{\varepsilon \mu}$ is the perimeter of tensile strain zone with the values $\varepsilon_{\mu}=\varepsilon_{\mu}^{\mathrm{k}}$ at its boundary.

The results of in-situ studies, and numerical and physical modeling, and their further calibration allow characterization (Fig. 4) of influence exerted by the geometry of conventional stopes and of the newly developed nature-like mine structures on the change of the initial stress field. For each mining system, the interpolation function of the influence factor is plotted to demonstrate stability rating of rock masses.

Based on the studies into stress-strain patterns in rock mass under mining using conventional [7-13] and new, environmentally sound convergent geotechnologies [14-16], recommendations on their design and adapting to certain geological conditions are developed.

Instrumentation of the integrated testing workbenches (Fig. 5) allowed plotting the experimental patterns of strength, deformation and acoustic characteristics of physical models of the test geotechnical systems (Fig. 6).

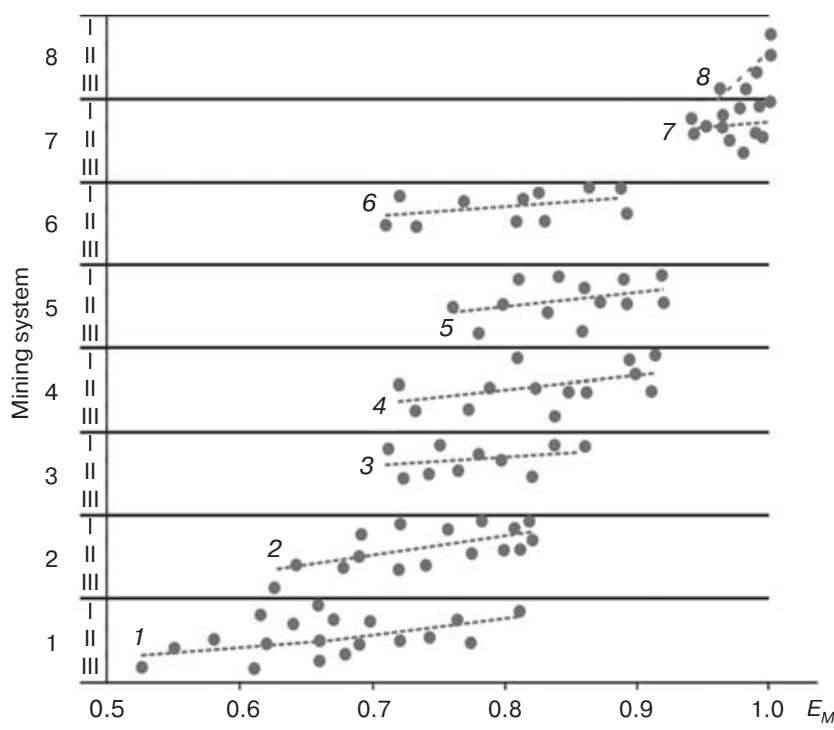

Fig. 4. Diagram of influence exerted by stope geometry on initial stress field:

1-8 - underground mining systems (block caving; sublevel caving; open stoping; stoping with backfill; cut-and-fill; room-andpillar; honeycomb mine structure with and without backfill; frame mine structure); I-III - rock mass stability categories: I - stable, II - medium-stable, III - unstable; 0.5-1 - influence factor
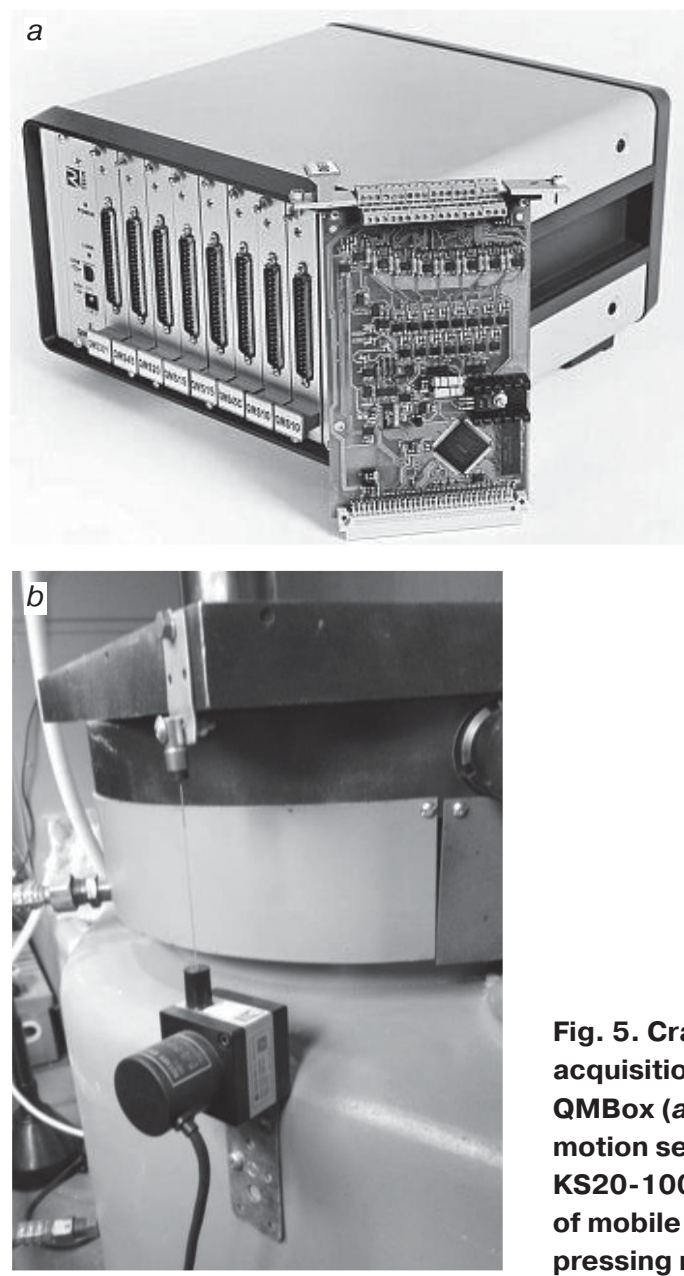

Fig. 5. Crate data acquisition system QMBox (a) and motion sensor KS20-1000-01-C2 of mobile plate of pressing machine $(b)$ 

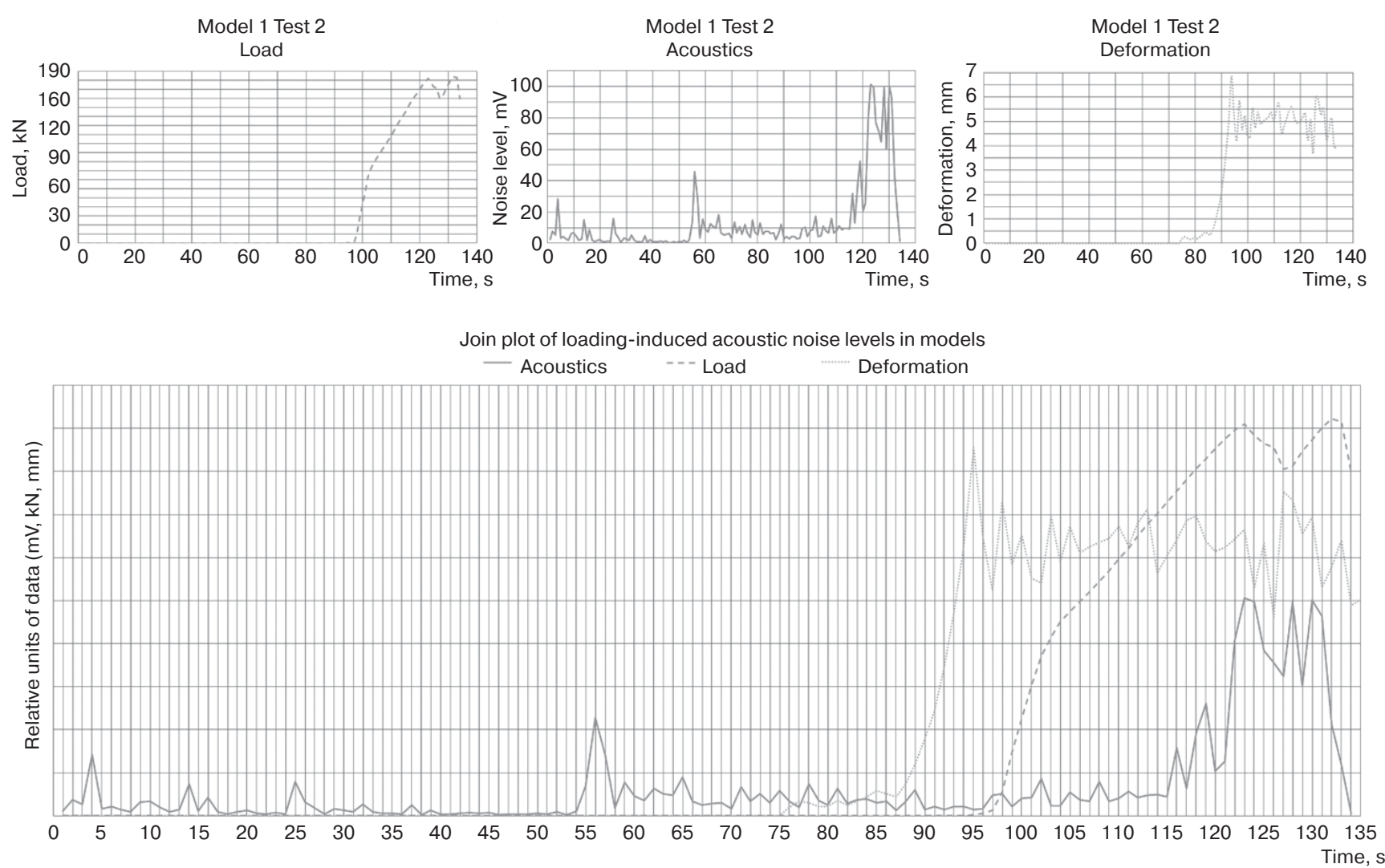

Fig. 6. Test data of physical model of frame mine structure: strength, deformation and acoustic characteristics, and loadinginduced acoustic noise overlay

Table 2. Average values of strength, deformation and acoustic characteristics obtained on physical models of frame mine structures

\begin{tabular}{|c|c|c|c|c|c|c|}
\hline $\begin{array}{l}\text { Mine } \\
\text { structure }\end{array}$ & Physical model & Maximal load, kN & $\begin{array}{c}\text { Maximal } \\
\text { deformation, } \mathrm{mm}\end{array}$ & $\begin{array}{c}\text { Ultimate } \\
\text { strength, } \mathrm{MPa}\end{array}$ & $\begin{array}{c}\text { Relative elongation, } \\
\%\end{array}$ & $\begin{array}{c}\text { Fracture-induced } \\
\text { noise level, mV }\end{array}$ \\
\hline- & Solid, no voids, glued & 440.857 & 5.817 & 11.021 & 2.983 & 96.25 \\
\hline- & Solid, no voids, non-glued & 623.755 & 5.769 & 15.594 & 2.958 & - \\
\hline \multicolumn{7}{|c|}{ Initial gravitational stress field } \\
\hline Frame & Model 1 & 186.542 & 3.754 & 4.664 & 1.925 & 101.18 \\
\hline Frame & Model 2 & 87.84 & 7.394 & 2.196 & 3.974 & 99.76 \\
\hline Frame & Model 3 & 178.364 & 9.474 & 4.459 & 3.434 & 93.64 \\
\hline Frame & Model 4 & 123.324 & 5.411 & 3.083 & 2.775 & 69.90 \\
\hline \multicolumn{7}{|c|}{ Initial lithostatic stress field } \\
\hline Frame & Model 1 & 242.505 & 3.003 & 6.063 & 1.54 & 121.416 \\
\hline Frame & Model 2 & 114.192 & 5.915 & 2.855 & 3.179 & 119.712 \\
\hline Frame & Model 3 & 231.873 & 7.579 & 5.797 & 2.747 & 112.368 \\
\hline Frame & Model 4 & 160.321 & 4.329 & 4.008 & 2.22 & 83.88 \\
\hline \multicolumn{7}{|c|}{ Initial gravitational tectonic stress field (deviatoric distribution of principal stresses) } \\
\hline Frame & Model 1 & 121.252 & 3.904 & 3.032 & 1.925 & 84.991 \\
\hline Frame & Model 2 & 57.096 & 7.69 & 1.427 & 3.974 & 83.798 \\
\hline Frame & Model 3 & 115.937 & 9.853 & 2.898 & 3.434 & 78.658 \\
\hline Frame & Model 4 & 80.161 & 5.627 & 2.004 & 2.775 & 58.716 \\
\hline
\end{tabular}



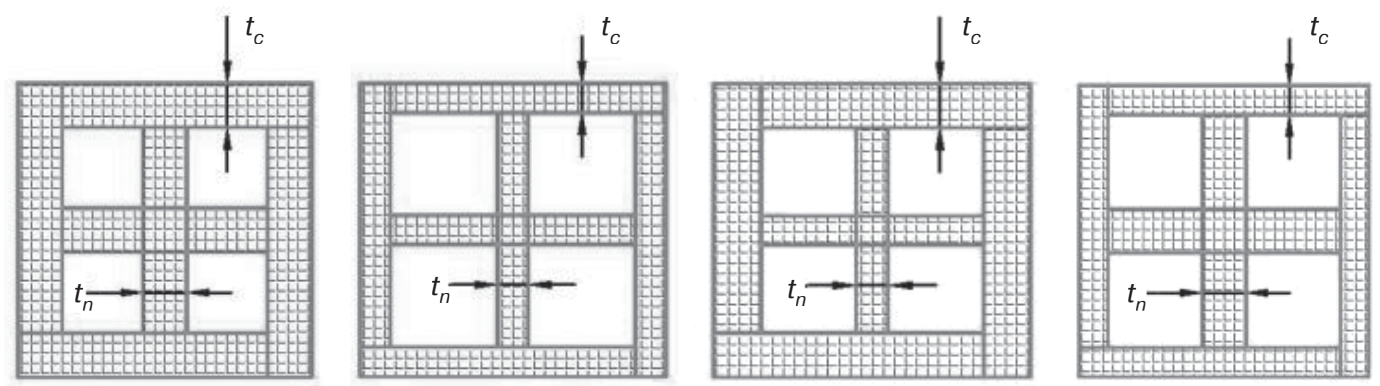

Fig. 7. Geometrical

parameters of models in central horizontal crosssection of frame mine structure

Table 2 compiles selected experimental data obtained on physical model of the frame mine structures made of equivalent material for different variants of the initial stress field generated using the designed integrated workbench for the physical and optical modeling of geophysical processes in the secondary stress fields.

The highest characteristics of strength of the frame and honeycomb mine structure models are recorded in the tests with the lithostatic initial stress state, while under the gravitational tectonic and under the gravitational stresses in case of deviatoric distribution of principal stresses, the strength characteristics essentially decrease (See Table 2). The percentage distribution of the areas of the material and voids (stopes) in the models (Fig. 7) describes their strength characteristics: when the area of the geomaterial in the model is larger, the model better resists the external loading. The thickness of the frame relative to the thickness of the intra-frame pillars (partitions) also has an influence on the strength of the models: with the higher frame thickness relative to the thickness of the partitions, the resisting strength of the model is higher (See Fig. 7).

For another thing, one more, result is obtained, which seems unevident at the first sight: the model composed of glued unit blocks has the ultimate strength in uniaxial loading smaller than the model composed of unglued blocks (See Table 2). The analysis and quantitative estimate reveal that the friction $\left(\Phi_{r}\right)$ at the interfaces of joints is much less in the glued model than in the unglued mode since the roughness of joints in the latter is 1.5 times higher. The cohesion (C) of the glued blocks has no influence on the strength of the model as the cohesion forces are an order of magnitude smaller than the friction forces at the joint interfaces in fracture. The strength of the models without voids is 1.9-10.5 times higher than in the models with voids (stopes) in any variant of the initial stress field.

The best strength and geotechnical characteristics are demonstrated by frame structure model 3 (See Fig. 7) under the lithostatic initial stress state.

The physical and numerical modeling included simulation of different variants of initial stress field: gravitational, lithostatic and gravitational tectonic, generated on a special workbench. We determined three parameters of the stress-strain behavior of the model ore and rock masses: factor of safety, microstrains and excessive stresses [17].

\section{Customization of numerical models}

The obtained values of the strength and deformation characteristics of the physical models made it possible to calibrate the numerical models based on the retrospective analysis of
Table 3. Calibrated values of microstrains for physical models

\begin{tabular}{|c|c|c|}
\hline Rock mass quality & Microstrain $\mu$ & Fracture opening, $\mathrm{mm}$ \\
\hline Crushed & $>500$ & $>5$ \\
\hline Heavily broken & $450-500$ & to 5 \\
\hline Broken & $350-450$ & to 2 \\
\hline Jointed & $250-350$ & $\sim 0-1$ \\
\hline Initiation of jointing & 150 & Indistinguishable \\
\hline
\end{tabular}

deformation and fracture processes in the physical models, as well as in-situ research (Table 3 ). The numerical stress-strain modeling of the new geotechnical systems was implemented for the specific geological conditions, with introduction of calibrated physical/mechanical and quantitative characteristics of lithological varieties in rock mass, as well as different variants of the initial stress field.

An indicator of the secondary stress field is assumed to be the microstrain $\varepsilon_{\mu}=\varepsilon \cdot 10^{6}$, where $\varepsilon=\Delta L / L$ is the relative tensile strain in rock mass, $\Delta L$ is the change of the initial size of an object being deformed, $m ; L$ is the initial size of the object being deformed, $m$. The laboratory research finds out that the first fractures both in rocks and in equivalent materials are detected at the tensile microstrains $\varepsilon_{\mu}=200$, which is a critical value of volumetric fracturing. In mines, the first tensile fractures are observed when $\varepsilon_{\mu} \approx 350$, and when the tensile microstrains increase to $500-800$, rock mass begins deforming intensly, with formation of roof areches and possible failure zones. For this reason, $\varepsilon_{\mu}^{k}=350$ is assumed as the numerical criterion to define the external boundary of the secondary stress field as this is the microstrain at which the first tesnile fractures are distinguished in rock mass.

The modeling revealed trouble spots in the structures and allowed optimizing parameters of the systems to be capable to effectively resist external loading.

As per the R\&D project plant and using the Terzaghi theory, we adapted the constructed numerical models of the new geotechnical systems to the conditions which limit application of Map3D, Dips, RocData, Unwedge and PicSure.

The stress-strain analysis of the test geotechnical systems was carried out in Map3D which uses the method of boundary integral equations, with the help of CAD system for the complex 3D modeling, analysis and visualization of lithostatic pressure and elastic strains at the boundaries of stopes, and in pillars and fill masses at different Q-index of rock mass and initial stress field.

The rock mass behavior under excessive stresses is analyzed using the Hoek-Brown failure criterion which is a function 
of the maximal and minimal values of the principal stresses, as well as strength characteristics of rocks. This criterion suits well to the application conditions of convergent technologies and the novel mine structures.

The Terzaghi approach enabled modeling and, then, calibration of the models of conventional geotechnical systems based on the quantitative assessment of real-life rock mass and using the physical modeling of rock fracture processes. During the research, we varied the values of the input parameters in the numerical models of the conventional geotechnical systems and ensured complete correspondence of layouts of tensile strain zones in the model and in the real-life rock mass. Then, the similar conditions were created in the numerical modeling of the new geotechnical systems. The modeling error in this case makes $10-15 \%$ as against the error of 40 to $60 \%$ in the estimate without calibration.

RocData was used to determine the physical and mechanical properties of real-life rock mass in the selected deposits (Hoek-Brown criterion). The results were involved in the stress-strain analysis in Map3D.

Dips was selected to process the quantitative estimates of rock mass behavior and the in-situ rock mass jointing studies (measured angles and azimuths of incidence of joints on exposed surfaces in underground openings using a circumferentor). We determined the number and systems of joints, their spatial characteristics, Q-index and the orientation of the maximum principal stress as the basic effective force using the rose-diagram of spatial orientation of joints. The obtained data were exported to Map3D for the numerical modeling calibration.

Unwedge was applied to identifying probable fracture wedges in sidewalls, roofs and floors of underground openings based on Dips-produced data on rock mass jointing. Again, the results were sent to calibrate Map3D models.

$\mathrm{Q}$-index of rock mass was determined in PicSure using core images.

Customization of the numerical models of the new geotechnical systems in Map3D, Dips, RocData and Unwedge made it possible to define the range of geological and geotechnical conditions suitable for application of the convergent mining technologies, as well as their optimized characteristics and quantitative variables.

\section{Conclusions}

The experimental research using the physical modeling methods prove their applicability to geomechanical studies connected with the development of nature-like mining technologies and frame and honeycomb mine structures. The physical models allow research within wide ranges of the initial stresses of rock masses and properties of equivalent materials.

The physical modeling-based studies into the secondary stress field impact on the structural components of the novel frame and honeycomb mine structures allowed calculating stable parameters of the structural components, revealing their trouble spots and identifying the further routes of creation of nature-like mining technologies, which can enable relevant design and engineering later on.

References

1. Kirpichev M. V. Theory of similarity. Moscow: AN SSSR, 1953. $93 \mathrm{p}$.
2. Glushikhin F. P., Kuznetsov G. N., Shklyarsky M. F. et al. Modeling in geomechanics. Moscow: Nedra, 1991. 240 p.

3. Pokrovsky G. I., Fedorov I. S. Centrifugal modeling to solve engineering problems. Moscow, 1953.

4. Galchenko Yu. P., Leizer V. I., Vysotin N. G., Yakusheva E. D. Procedure justification for laboratory research of secondary stress field in creation and application of convergent technology for underground mining of rock salt. GIAB. 2019. No. 11. pp. 35-47.

5. Zuev B. Yu., Istomin R. S., Kovshov S. V., Kitsis B. M. Physical modeling the formation of roof collapse zones in Vorkuta coal mines. Bulletin of the Mineral Research and Exploration. 2020. No. 1. pp. 225-234.

6. Rib S. V., Govorukhin Yu. M. Integrated research method for geomechanical processes by combining physical and numerical modeling. Izvestiya TuIGU. Nauki o Zemle. 2018. No. 2. pp. 363-378.

7. Sidorov D., Ponomarenko T. Reduction of the ore losses emerging within the deep mining of bauxite deposits at the mines of OJSC Sevuralboksitruda. IOP Conference Series: Earth and Environmental Sci. 2019. 302. 012051. DOI: 10.1088/17551315/302/1/012051

8. Aptukov V. N., Volegov S. V. Modeling concentration of residual stresses and damages in salt rock cores. Journal of Mining Science. 2020. Vol. 56. No. 3. pp. 331-338.

9. Rybin V. V., Konstantinov K. N., Kagan M. M., Panasenko I. G. Methodology of integrated stability monitoring in mines. Gornyi Zhurnal. 2020. No. 1. pp. 53-57. DOI: 10.17580/gzh.2020.01.10

10. Eremenko A. A., Konurin A. I., Shtirts V. A., Prib V. V. Identification of higher rock pressure zones in rockburst-hazardous iron ore deposits. Gornyi Zhurnal. 2020. No. 1. pp. 78-81. DOI: 10.17580/gzh.2020.01.15

11. Yu L., Ignatov Y., Ivannikov A., Khotchenkov E., Krasnoshtanov D. Common features in the manifestation of natural and induced geodynamic events in the eastern regions of Russia and China. IOP Conference Series: Earth and Environm ental Science. 2019. Vol. 324(1),012004. DOI: 10.1088/1755$1315 / 324 / 1 / 012004$

12. Kong L., Ostadhassan M., Li C., Tamimi N. Rock physics and geomechanics of 3D printed rocks. ARMA 51st U.S. Rock Mechanics and Geomechanics Symposium. San Francisco, California, USA, 2017. pp. 1-8.

13. Gell E. M., Walley S. M, Braithwaite C. H. Review of the validity of the use of artificial specimens for characterizing the mechanical properties of rocks. Rock Mechanics and Rock Engineering. 2019. No. 3. pp. 1-13.

14. Trubetskoy K. N., Myaskov A. V., Galchenko Yu. P., Eremenko V. A. Creation and justification of convergent technologies for underground mining of thick solid mineral deposits. Gornyi Zhurnal. 2019. No. 5. pp. 6-13. DOI: 10.17580/ gzh.2019.05.01

15. Trubetskoy K. N., Galchenko Yu. P. Nature-like geotechnology for integrated subsoil use: Problems and prospects. Moscow: Nauchtekhlitizdat, 2020. 368 p.

16. Myaskov A. V. Methodological framework for the ecological and economic justification of preservation of natural ecosystems in mining regions. GIAB. 2011. No. 1. pp. 399-401.

17. Eremenko V. A., Galchenko Yu. P., Vysotin N. G., Leizer V. I., Kosyreva M. A. Strength, deformation and acoustic characteristics of physical models of frame and honeycomb underground structures. Journal of Mining Science. 2020. Vol. 56. No. 6. pp. 962-971. 